\title{
FURTHER STUDIES ON THE VARIATION OF SPRAY DEPOSITS IN VINEYARDS WITH AIRFLOW RATE AND VOLUME RATE
}

\author{
Emanuele Cerruto
}

\section{Introduction}

Along with the technical features of the sprayers, some working conditions as forward speed, airflow rate, and volume rate, are among the parameters deeply influencing the results of a spray application.

Though the positive effects of airflow rate are unanimously recognised, the choice of the correct amount is still investigated, as it is related to many factors (crop, growth stage, layout). Many Authors $[7,4,8]$ report that an increase in the airflow rate generally improves the spray penetration, but leads to higher losses and higher power requirements. The Author in recent tests [2] carried out in a hedgerow vineyard, found that airflow rates of some 3.9 and 7.5 $\mathrm{m}^{3} / \mathrm{s}$ do not influence significantly the average deposits, but the highest value of airflow rate improves the penetration of the spray jet only at full foliage development. In this paper further results on this topic are reported, investigating the effects of the same airflow rates, along with that of the volume rates.

Volume application rate is another important factor influencing the real work capacity of the sprayers and the quality of the deposition. Several mathematical models are reported in literature to determine the optimal volume rate, among which can be mentioned [5]: - ground area:

$$
Q[\mathrm{~L} / \mathrm{ha}]=10^{4} \frac{q[\mathrm{~L} / \mathrm{s}]}{d[\mathrm{~m}] \cdot v[\mathrm{~m} / \mathrm{s}]}
$$

where $q$ is the flow rate of all the nozzles, $d$ the working width, and $v$ the forward speed;

- canopy volume:

$$
Q[\mathrm{~L} / \mathrm{ha}]=T R V\left[\mathrm{~m}^{5} / \mathrm{ha}\right] \cdot\left[\mathrm{L} / \mathrm{m}^{3}\right]
$$

where TRV is the "Tree Row Volume" (volume of

Paper received 09.05.2006; accepted 14.10.2006

Prof. Ing. Emanuele Cerruto, Associate Professor (ecerruto@ unict.it), Dipartimento di Ingegneria Agraria, University of Catania, Italy.

Research developed within the 2001 MIUR project "Improvement of Deposition Efficiency of Vineyard Sprayers", prot. 2001073192. canopy per hectare) and $i$ the application rate, expressed as litres of mixture per cubic meter of canopy; - optimal covering:

$$
Q[\mathrm{~L} / \mathrm{ha}]=\frac{K \cdot 2 \cdot L A I-\hat{N}\left[\mathrm{em}^{-2}\right] \cdot \frac{\pi}{6} \cdot d_{N}^{3}\left[\mathrm{~mm}^{3}\right] \cdot 10^{-3}}{R}
$$

where $L A I$ is the leaf area index, $\hat{N}$ the optimum impact density per square centimetre, $d_{m}$ the average diameter of the droplets expressed as VMD ("Volume Median Diameter"), $R$ the recovery factor, and $K$ a suitable corrective coefficient, depending on the drops pulverisation.

To obtain adequate results, it is important a precise selection of the critical factors application rate $i$ in Eq. (2) and VMD $d_{m}$ in Eq. (3). Walklate et al., [9], working on apple orchards, propose a generalisation of Eq. (1) in the form:

$$
Q\left[\mathrm{~L} / \mathrm{m}^{2}\right]=\frac{q / v[\mathrm{~L} / \mathrm{m}]}{L[\mathrm{~m}]}
$$

where the ratio $q / v$ is the volume application rate on a unit row length basis and $L$ is a suitable length-scale that describes the scaling effect of the crop structure. The Authors propose as the best $L$ parameter, interpreting the highest variation in deposits, the tree area density, which can be either measured or estimated via suitable pictographs.

Experimental tests carried out in apple orchards [3] showed that wide variation in spray liquid flow rate (from 3.8 to $29 \mathrm{~L} / \mathrm{min}$ ) has only small effects on normalised spray deposits on the tree, on spray drift and on losses to the ground. On the contrary, it greatly affects spray cover, which varies in proportion to the spray liquid flow rate.

Pergher and Gubiani [6], operating in a hedgerow vineyard, found that increasing spray application rate leads to greater ground losses and lower foliar deposition, especially at full foliage development.

The objective of this study is to provide further results on the influence of airflow rates and volume rates on foliar deposition from an air-assisted sprayer in a Sicilian hedgerow vineyard, considering also the growth stage of the vegetation. 


\section{Materials and methods}

\subsection{The vineyard}

Field tests were carried out in a spur-cordon vineyard ("cordone speronato"), cv "Nero d'Avola", with a layout of $2.50 \times 1.25 \mathrm{~m}$, in two phenological stages: "Inflorescences fully developed" (code 57 of the BBCH scale, 15 May 2003), and "Beginning of berry touch" (code 77 of the BBCH scale, 4 July 2003). The tests were performed according to a procedure very similar to that described in [2], here briefly summarised for completeness.

The main geometrical features of the trees (maximum and minimum height of the vegetation, cordon height, thickness of the vegetation, LAI) were measured the day before the field tests. The geometrical profile was adopted as a reference profile to calibrate the sprayer by means of a vertical tray patternator [1].

In the first stage, due to the little development of the vegetation, the canopy of each sample tree was divided into two equally spaced heights (low and high), and two depth zones (left and right side, assumed symmetric). In the second stage, the canopy was divided into three heights (low, middle and high), and four depth zones (external and internal of the left and right side, with the two sides again assumed to be symmetric).

The LAI of the first stage was calculated counting the leaves of 24 trees, picking a leaf every ten, and measuring the surface of the sampled leaves by means of an image analysis system. In the second stage, the LAI was computed defoliating four trees and using the relation between mass and foliar surface. The procedure was performed according to:

1. defoliate each of the six zones established on one side of the canopy, putting the leaves in distinct suitably labelled plastic bags;

2. select randomly two leaves in each bag and measure their mass and surface. The mass was measured by means of a precision balance and the surface by means of an image analysis system;

3 . derive a regression between mass and surface of the selected leaves;

4. estimate the overall surfaces of the leaves in each bag, using the relationship previously determined. As this relationship was found to be linear, the computation was performed according to:

a) determine the overall mass of the leaves in each bag;

b) count the number of leaves in each bag;

c) determine the average mass $\overline{\mathrm{m}}$ of a leaf;

d) estimate the corresponding surface $\bar{S}$ by means of the equation of regression;

e) estimate the overall foliar surface as $\bar{S}$ number of leaves;

5. compute the $L A I$ of each zone dividing the foliar surface by the ground surface;

6. compute the number of foliar layers $n L$ of each zone as:

$$
n L=\frac{a \times L A I}{4 h}
$$

where $a$ is the distance between rows and $\Delta h$ the height of each zone.

\subsection{The sprayer and the field tests}

Field tests were carried out using the same sprayer described in [2]: an air assisted towed sprayer, fitted with a $0.80 \mathrm{~m}$ diameter axial fan and 2 vertical spray booms, equipped with 7 nozzles per side. Only 2 and 3 nozzles per side were switched on, at the first and the second growth stage respectively. Their orientation was settled by means of a vertical spray patternator, so to reproduce the geometric profile of the canopy.

A full factorial experiment was carried out, with two airflow rates, three volume rates, and four replicates, arranged according to a randomised complete block design. Forward speed and pressure were kept constant $(1.4 \mathrm{~m} / \mathrm{s}$ and 1.2 $\mathrm{MPa}$ respectively). To obtain different volume rates, "Albuz ATR" nozzles with different orifice diameter were used: lilac $(0.8 \mathrm{~mm})$, yellow $(1.2 \mathrm{~mm})$, and orange $(1.5 \mathrm{~mm})$. Table $1 \mathrm{re}-$ ports a summary of the experimental tests.

Applications were performed distributing a water solution with $3 \%$ of food dye Poinceau Red as a tracer and $0.05 \%$ of Agral as a surfactant, with just one spray pass for each replicate, after opening the nozzles on the right-hand side of the sprayer only. After spray application, 6 leaves were randomly picked on each sample zone. Sampling was carried out on both sides of the trees in the first growth stage (internal layer $=$ sprayed side; external layer $=$ unsprayed side) and only on the sprayed side in the second growth stage, so to collect 576 (first stage) and 864 (second stage) leaves.

The foliar deposition was measured by means of a spectrophotometric technique [2] and was normalised to a fixed volume rate of $350 \mathrm{~L} / \mathrm{ha}$, so to allow some comparison with the results previously obtained. The data was statistically analysed applying the analysis of variance (ANOVA), carried out according to a split-plot design with two main plot factors (airflow rate and volume rate) and two sub-plot factors (height and depth of sampling). In reporting average deposition, the normalised unitary deposits were weighted according to the LAI of the belonging zone.

\begin{tabular}{|c|c|c|c|}
\hline \multirow{2}{*}{$\begin{array}{c}\text { Airflow } \\
\text { rate, } \\
\mathrm{m}^{3} / \mathrm{s}\end{array}$} & \multirow{2}{*}{$\begin{array}{c}\text { Nozzles } \\
\text { diameter. } \\
\text { mm }\end{array}$} & \multicolumn{2}{|c|}{$\begin{array}{c}\text { Volume rate, } \\
\text { Lha }\end{array}$} \\
\hline & & Stage 1 & Stage 2 \\
\hline $\mathrm{A}_{1}=3.9$ & 0.8 & $V_{1}=103$ & $V_{1}=154$ \\
\hline$A_{1}=3.9$ & 1.2 & $v_{2}=216$ & $V_{2}=330$ \\
\hline$A_{1}=3.9$ & 1.5 & $V_{3}=279$ & $V_{3}=432$ \\
\hline $\mathrm{A}_{2}=7.5$ & 0.8 & $V_{1}=103$ & $V_{1}=154$ \\
\hline $\mathrm{A}_{2}=7.5$ & 1.2 & $y_{z}=216$ & $V_{2}=330$ \\
\hline $\mathrm{A}_{2}=7.5$ & 1.5 & $V_{3}-279$ & $V_{3}=432$ \\
\hline
\end{tabular}

TABLE 1 - Summary of the experimental tests. 


\section{Results and discussion}

\subsection{Morphological measures of the vineyard}

Figure 1 reports the linear relationship between foliar mass and surface. The coefficient of determination $\mathrm{R}^{2}=0.9079$ was highly significant $(\mathrm{p}<0.001)$.

Geometric and LAI profiles of the trees at the two growth stages are reported in Figures 2 and 3 (mean on 24 trees). It is evident, in the first stage, the little development of the vegetation in the high zone (LAI only $0.10 \mathrm{~m}^{2} / \mathrm{m}^{2}$ ).

The overall LAI was $0.52 \mathrm{~m}^{2} / \mathrm{m}^{2}$ at stage 1 and $1.70 \mathrm{~m}^{2} / \mathrm{m}^{2}$ at stage 2 . Table 2 reports the average number of foliar layers at the two growth stages.

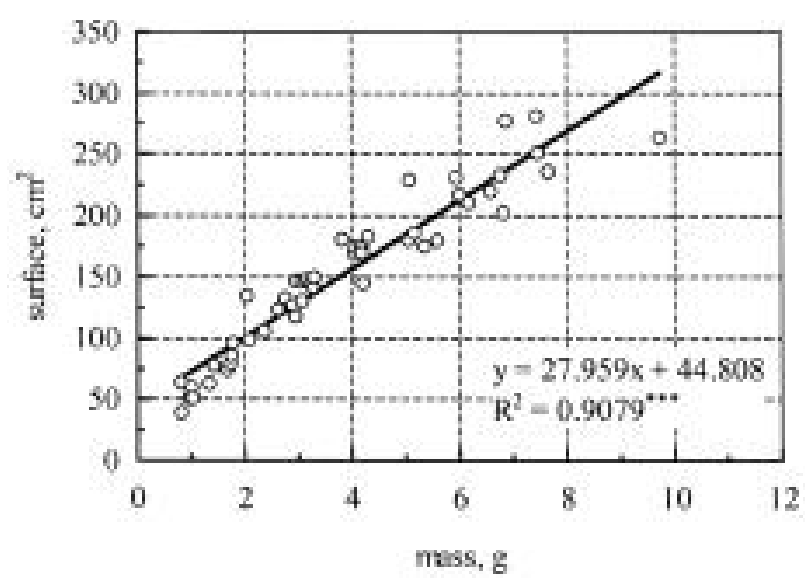

Fig. 1 - Linear relationship between foliar mass and surface.

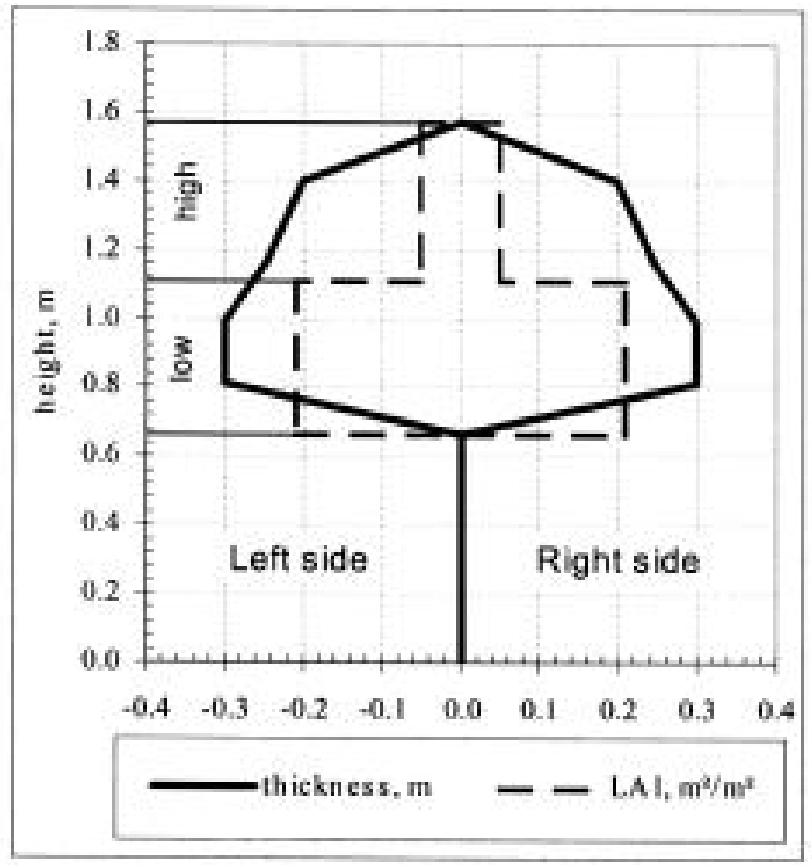

Fig. 2 - Stage 1: Average geometric and total LAI profiles of the trees.

\begin{tabular}{|ll|ll|}
\hline \multicolumn{2}{|c|}{ Stage 1 } & \multicolumn{2}{c|}{ Stage 2 } \\
\hline Left high & 0.3 & External high & 1.4 \\
Right high & 0.3 & lnternal high & 3.0 \\
Total high & 0.6 & Total high & 4.4 \\
& & External middle & 2.3 \\
& & Internal middle & 2.7 \\
& & Total middle & 5.0 \\
Left low & 1.2 & External low & 1.4 \\
Right low & 1.2 & lnternal low & 1.8 \\
Total low & 2.4 & Total low & 3.2 \\
Total & 1.5 & Total & 4.2 \\
\hline
\end{tabular}

TABLE 2 - Average number of foliar layers of the trees.

\subsection{Measures on the sprayer}

The average air velocity in output, $1.25 \mathrm{~m}$ apart from the fan axis, in the range $0.50-1.70 \mathrm{~m}$, corresponding to the presence of vegetation, was $9.4 \mathrm{~m} / \mathrm{s}$ with $3.9 \mathrm{~m}^{3} / \mathrm{s}$, and $18.2 \mathrm{~m} / \mathrm{s}$ with $7.5 \mathrm{~m}^{3} / \mathrm{s}$.

The distribution profiles, as established by means of a vertical tray patternator, are reported in Figures 4 and 5 (stage 1) and Figures 6 and 7 (stage 2). In both stages, the thickness of the vegetation was adopted as a reference profile. The distribution profiles are expressed as percentage of liquid collected by each tray.

\subsection{Foliar deposition - Stage 1}

Spray applications were performed between 9.30 and 11.38; average air temperature was $28{ }^{\circ} \mathrm{C}(\mathrm{min}=$ $24{ }^{\circ} \mathrm{C}, \max =32{ }^{\circ} \mathrm{C}$ ), average HR $26 \%(\min =20 \%$, $\max =29 \%)$, and average wind velocity $1.1 \mathrm{~m} / \mathrm{s}(\mathrm{min}$ $=0.5 \mathrm{~m} / \mathrm{s}, \max =1.7 \mathrm{~m} / \mathrm{s}$ ).

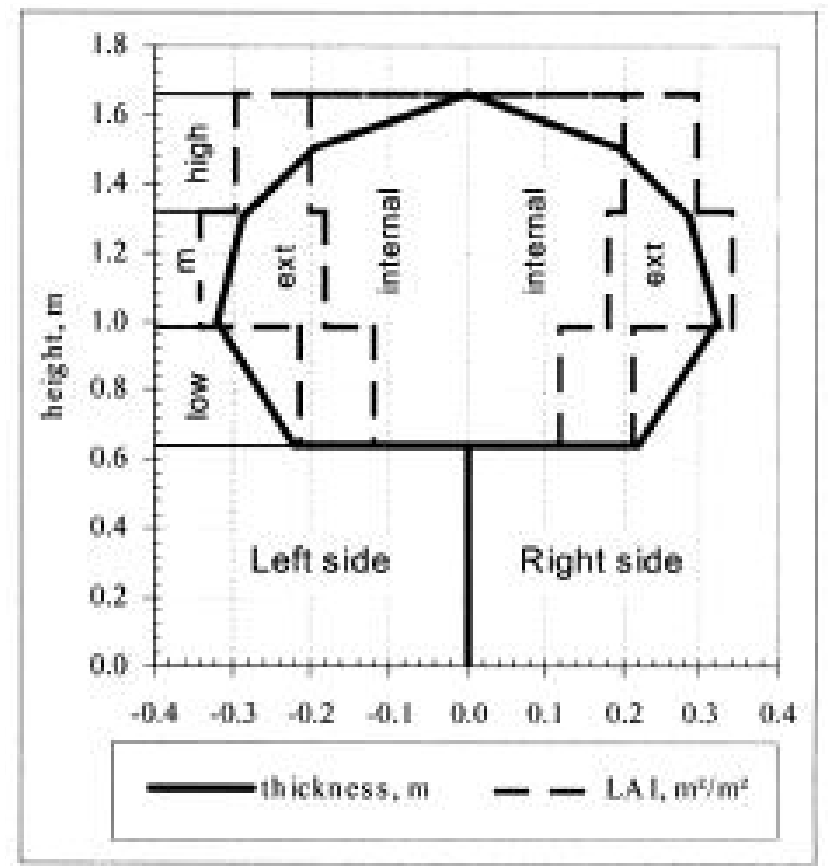

Fig. 3 - Stage 2: Average geometric, internal and total LAI profiles of the trees. $\mathrm{m}=$ middle height; ext $=$ external layer. 
thickness, $m$

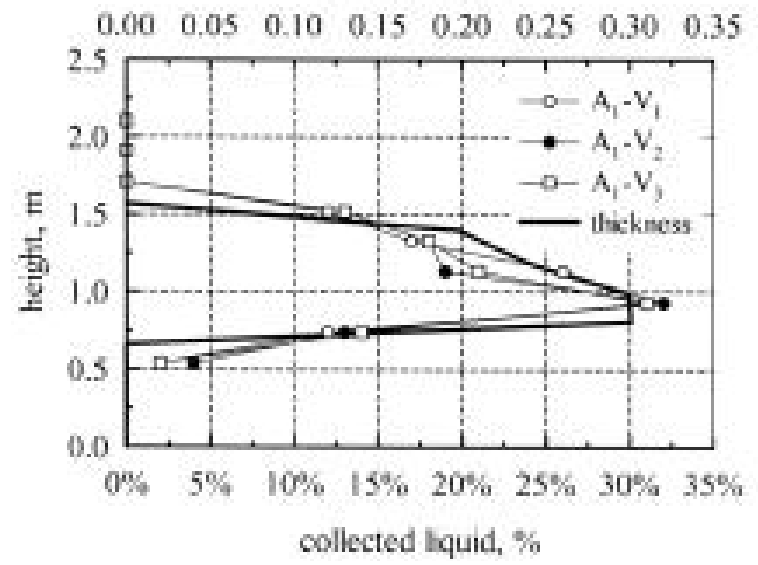

Fig. 4 - Stage 1: Distribution profiles with $\mathrm{A}_{1}=3.9 \mathrm{~m}^{3} / \mathrm{s}$.

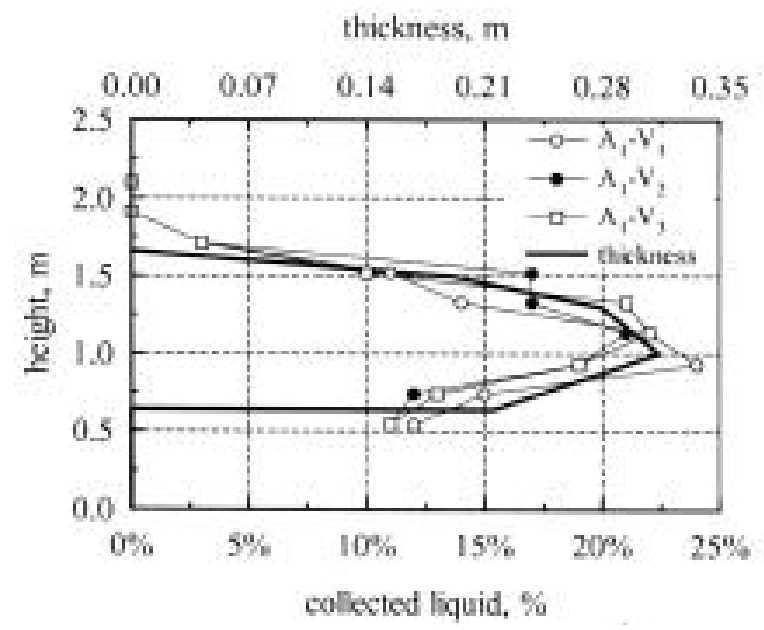

Fig. 6 - Stage 2: Distribution profiles with $\mathrm{A}_{1}=3.9 \mathrm{~m}^{3} / \mathrm{s}$.

A logarithmic transformation was applied to the raw data to normalise the frequency distribution and equalise the variances. The ANOVA table is reported in Table 3

It shows that neither airflow rate, nor volume rate significantly influence the normalised foliar deposits.

The average deposition vs the airflow rate is reported in Figure 8, almost equal to that obtained in the previous study [2]. This confirms the opportunity to operate in field, before full foliage development, at low airflow rates (some $3.9 \mathrm{~m}^{3} / \mathrm{s}$ ), so to reduce the spray drift and the power requirements. Figure 9 reports the average foliar deposit vs the volume rate. The highest depositions (not significantly different) were recorded at the intermediate volume rate: $0.398 \mu \mathrm{L} / \mathrm{cm}^{2}$.

These average results suggest the opportunity to operate in field at low volume rate, so to increase the working capacity and the promptness of intervention. However, the airflow $\times$ volume interaction (Fig. 10), though not statistically significant, shows a great reduction in foliar deposition at $103 \mathrm{~L} / \mathrm{ha}$ and $7.5 \mathrm{~m}^{3} / \mathrm{s}$, confirming that low volume rates along with high airflow rates increase the spray drift and reduce the fo-

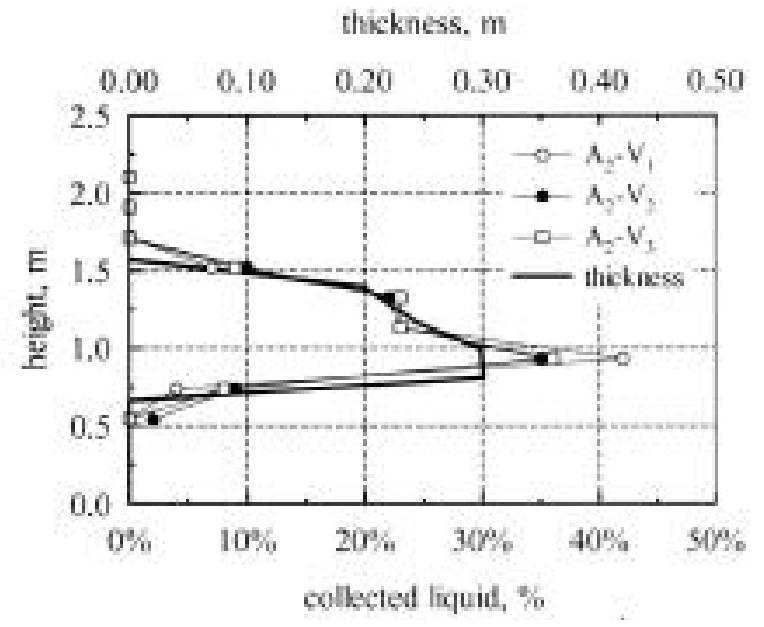

Fig. 5 - Stage 1: Distribution profiles with $\mathrm{A}_{2}=7.5 \mathrm{~m}^{3} / \mathrm{s}$.

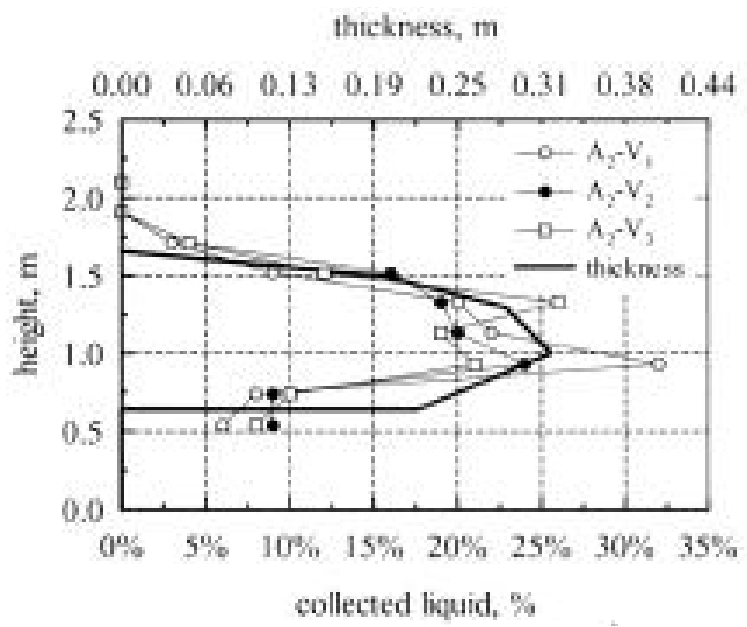

Fig. 7 - Stage 2: Distribution profiles with $\mathrm{A}_{2}=7.5 \mathrm{~m}^{3} / \mathrm{s}$.

liar deposits.

The sub-plot analysis shows the presence of significant differences only between sprayed and unsprayed side, influenced by the height zones (interaction depth $\times$ height significant at $\mathrm{p}<0.01$ ). The average deposition on the external layer was $0.542 \mu \mathrm{L} / \mathrm{cm}^{2}$, that on the internal one $0.137 \mu \mathrm{L} / \mathrm{cm}^{2}$. Examining the interaction (Fig. 11), it emerges that on the sprayed side the greatest deposition is on the low zone, while on the unsprayed one the greatest deposition is on the high zone. This is certainly due to the geometry of the vegetation: the thickness of the low zone, much greater than that of the high one, makes it difficult the spray jet penetration.

\subsection{Foliar deposition - Stage 2}

In the second stage, spray applications were performed between 8.12 and 9.01; average air temperature was $32{ }^{\circ} \mathrm{C}\left(\min =30{ }^{\circ} \mathrm{C}\right.$, $\left.\max =34^{\circ} \mathrm{C}\right)$, average HR $32 \%(\min =27 \%, \max =38 \%)$, and average wind velocity $0.4 \mathrm{~m} / \mathrm{s}(\min =0.2 \mathrm{~m} / \mathrm{s}, \max =0.9 \mathrm{~m} / \mathrm{s})$.

Raw data was transformed according to the power equation: 


\begin{tabular}{|c|c|c|c|c|c|}
\hline Source & SS & df & MS & $\mathbf{F}$ & p-level \\
\hline \multicolumn{6}{|c|}{ Main plot analysis } \\
\hline Replicate & 8.5277 & 3 & 2.8426 & & \\
\hline Air $(A)$ & 2.2480 & 1 & 2.2480 & 1.377 & $0.259^{6}$ \\
\hline Volume (V) & 2.1603 & 2 & 1.0801 & $<1$ & $0.530^{2 x}$ \\
\hline$A \times V$ & 1.5112 & 2 & 0.7556 & $<1$ & $0.638^{\mathrm{an}}$ \\
\hline Error (1) & 24,4826 & 15 & 1.6322 & & \\
\hline \multicolumn{6}{|c|}{ Sub-plot analysis } \\
\hline Height $(\mathrm{H})$ & 1.2780 & 1 & 1.2780 & 1.667 & $0.202^{m}$ \\
\hline Depth (D) & 185,370 & 1 & 185.370 & 241.731 & $0.000^{*+}$ \\
\hline$H \times D$ & 25.3254 & 1 & 25.3254 & 33.025 & $0.000^{\prime \prime \prime}$ \\
\hline$A \times H$ & 0.1931 & 1 & 0.1931 & $<1$ & $0.618^{\mathrm{m}}$ \\
\hline$A \times D$ & 0.1507 & 1 & 0.1507 & $<1$ & $0.65 y^{m}$ \\
\hline $\mathrm{V} \times \mathrm{H}$ & 2.4504 & 2 & 1.2252 & 1.598 & $0.212^{m}$ \\
\hline$V \times D$ & 3.2182 & 2 & 1.6091 & 2.098 & $0.133^{\mathrm{k}}$ \\
\hline$A \times H \times D$ & 1.0000 & 1 & 1.0000 & 1.304 & $0.259^{\circ}$ \\
\hline $\mathrm{V} \times \mathrm{H} \times \mathrm{D}$ & 2.0873 & 2 & 1.0437 & 1.361 & $0.265^{10}$ \\
\hline$A \times V \times H$ & 2.2173 & 2 & I.1086 & 1.446 & $0.245^{\mathrm{m}}$ \\
\hline$A \times V \times D$ & 0.7393 & 2 & 0.3696 & $<1$ & $0.620^{\prime \prime}$ \\
\hline$A \times V \times H \times D$ & 0.6934 & 2 & 0.3467 & $<1$ & $0.63 \%^{n}$ \\
\hline Emor 2) & 41.4005 & 34 & 0.7668 & & \\
\hline Sampling & 138.988 & 480 & 0.2896 & & \\
\hline
\end{tabular}

$\mathrm{CV}(1)=84 \% ; \mathrm{CV}(2)=57 \% ; * * *$ : significant at $\mathrm{p}=0.1 \%$; ns: not significant

TABLE 3 - Stage 1: ANOVA of the normalised deposits.

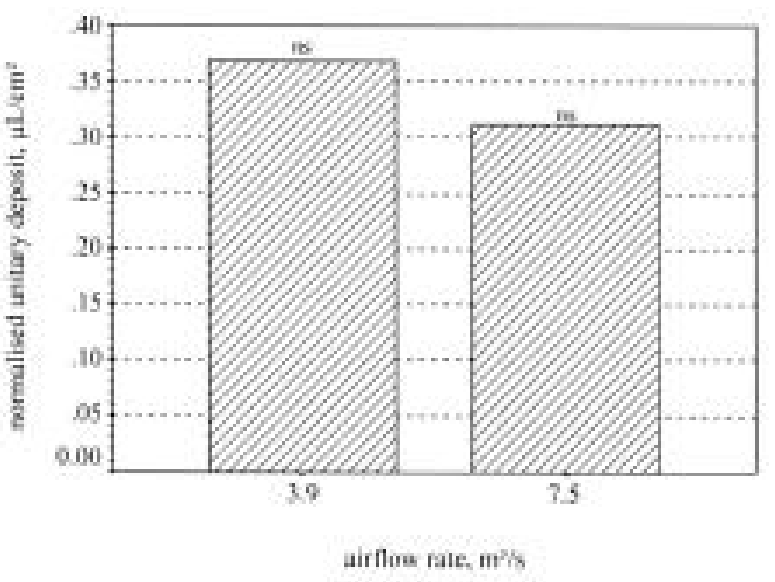

Fig. 8 - Stage 1: Normalised unitary deposit vs airflow rate. (ns: not significant).

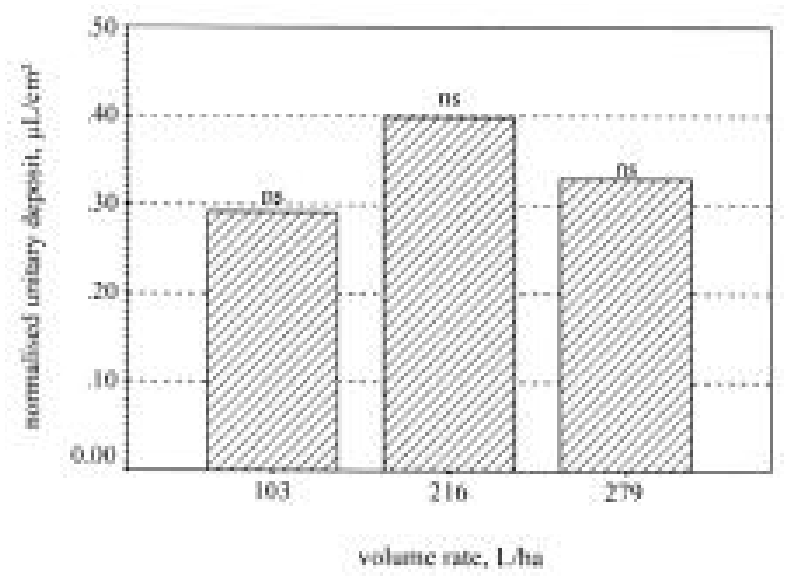

Fig. 9 - Stage 1: Normalised unitary deposit vs volume rate. (ns: not significant).

$$
\mathrm{d}_{\mathrm{nt}}=\mathrm{d}_{\mathrm{n}}^{0.2}
$$

to normalise the frequency distribution and equalise the variances.

The results of the analysis of variance are reported in Table 4. They show some differences compared to the first stage, mainly due to the airflow rate. In fact, while the volume rate is still not affecting the average mean deposition $(p=0.573$, Fig. 12), the airflow rate has a significant influence $(\mathrm{p}<0.01$, Fig. 13). The greatest average foliar deposition is obtained at 3.9 $\mathrm{m}^{3} / \mathrm{s}$, confirming the opportunity to operate in field at low airflow rates. This result, based on the average foliar deposition, is also in agreement with that obtained in the previous research [2].

The sub-plot analysis shows that the airflow rate interacts with the sampling depth only $(p=0.002)$. Examining the interaction (Fig. 14), it emerges that increasing the airflow rate does not improve the deposition in the inner layer of the canopy. This result is in disagreement with that reported in [2], and could be explained by the pruning operations performed on the canopy a few days before the previous experimental trials. Further experiments are necessary to better understand this aspect.

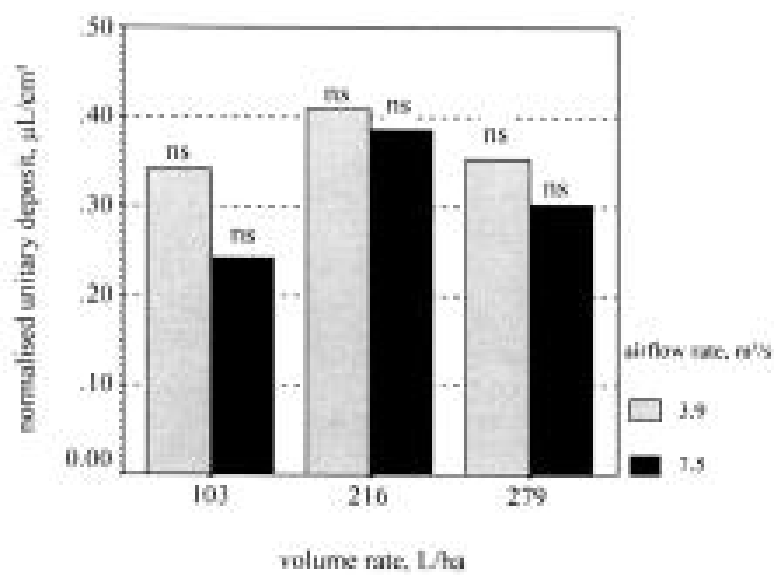

Fig. 10 - Stage 1: Normalised unitary deposit vs volume and airflow rate. (ns: not significant).

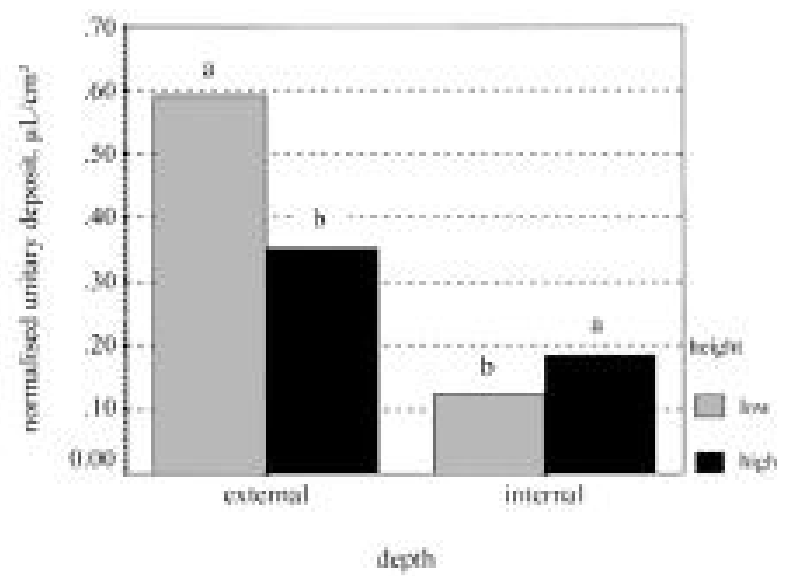

Fig. 11 - Stage 1: Normalised unitary deposit on the two depths (Mean separation at each depth by Tukey's test at 5\% level). 


\begin{tabular}{|c|c|c|c|c|c|}
\hline Source & SS & df & MS & $\mathbf{F}$ & p-level \\
\hline \multicolumn{6}{|c|}{ Main plot analysis } \\
\hline Replicate & 1.0435 & 3 & 0.3478 & & \\
\hline Air (A) & 0.7431 & 1 & 0.7431 & 20.633 & $0.0000^{\circ}$ \\
\hline Volume (V) & 0.0417 & 2 & 0.0208 & $<1$ & $0,573^{*}$ \\
\hline$A \times V$ & 0.0248 & 2 & 0.0124 & $<1$ & $0.714^{26}$ \\
\hline Erron( () & 0.5402 & 15 & 0.0360 & & \\
\hline \multicolumn{6}{|c|}{ Sub-plot analysis } \\
\hline Height $(\mathrm{H})$ & 0.4842 & 2 & 0.2421 & 15.593 & $0.000^{\mathrm{m}}$ \\
\hline Depth (D) & 3,1738 & 1 & 3.1738 & 204.431 & $0.000^{* *}$ \\
\hline$H \times D$ & 0.3772 & 2 & 0.1886 & 12.147 & $0.000^{* * t}$ \\
\hline$A \times H$ & 0.0705 & 2 & 0.0352 & 2.269 & $0.109^{11}$ \\
\hline$A \times D$ & 0,1511 & 1 & 0.1511 & 9.736 & $0.002^{4 t}$ \\
\hline $\mathrm{V} \times \mathrm{H}$ & 0.2443 & 4 & 0.0611 & 3.934 & $0.005^{*+}$ \\
\hline$V \times D$ & 0.1073 & 2 & 0.0536 & 3.455 & $0.036^{*}$ \\
\hline$A \times H \times D$ & 0.0321 & 2 & 0.0161 & 1.035 & $0.35 y^{\prime \prime}$ \\
\hline $\mathrm{V} \times \mathrm{H} \times \mathrm{D}$ & 0.0413 & 4 & 0.0103 & $<1$ & $0.618^{\circ}$ \\
\hline $\mathrm{A} \times \mathrm{V} \times \mathrm{H}$ & 0.0315 & 4 & 0.0079 & $<1$ & $0.731^{\mathrm{m}}$ \\
\hline$A \times V \times D$ & 0.0109 & 2 & 0.0054 & $\Leftrightarrow 1$ & $0.706^{\mathrm{m}}$ \\
\hline$A \times V \times H \times D$ & $0.0206^{\circ}$ & 4 & 0.0052 & $<1$ & $0.856^{\mathrm{m}}$ \\
\hline Error(2) & 1.3973 & 90 & 0.0155 & & \\
\hline Sampling & 4.5178 & 720 & 0.0063 & & \\
\hline
\end{tabular}

$\mathrm{CV}(1)=24 \% ; \mathrm{CV}(2)=16 \%$; ***: significant at $\mathrm{p}=0.1 \%$; **: significant at $\mathrm{p}=1 \%$; *: significant at $\mathrm{p}=5 \%$; ns: not significant

TABLE 4 - Stage 2: ANOVA of the normalised deposits.

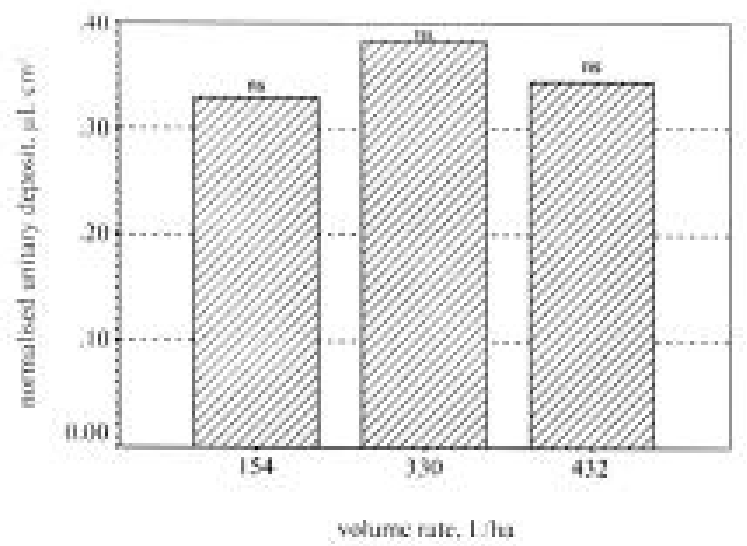

Fig. 12 - Stage 2: Normalised unitary deposit vs volume rate. (ns: not significant).

Volume rate significantly interacts with both depth $(\mathrm{p}=0.036)$ and height $(\mathrm{p}=0.005)$. The first interaction (Fig. 15) shows a lower deposition on the external layer with $154 \mathrm{~L} / \mathrm{ha}$, while the second one (Fig. 16) shows a lower deposition on the low part of the canopy at 330 and $432 \mathrm{~L} / \mathrm{ha}$. As a consequence, also the height $\times$ depth interaction, significant at $\mathrm{p}<0.01$, shows a lower deposition on the low-external layer of the trees (Fig. 17). These results, very hard to explain, could be related to the distribution profiles and the different drops pulverisation realised by the nozzles.

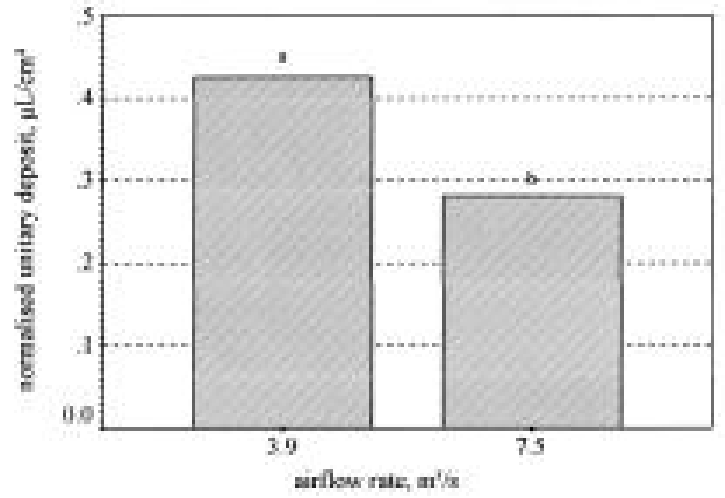

Fig. 13 - Stage 2: Normalised unitary deposit vs airflow rate. (Mean separation by Tukey's test at $5 \%$ level).

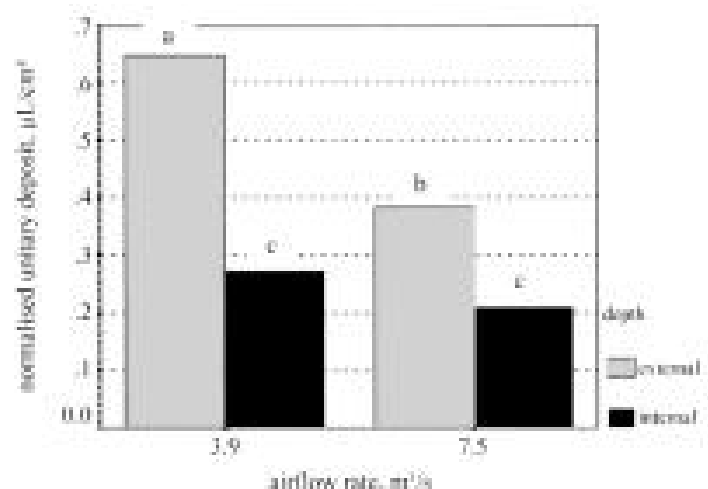

Fig. 14 - Stage 2: Normalised unitary deposit vs airflow rate. (Mean separation by Tukey's test at $5 \%$ level).

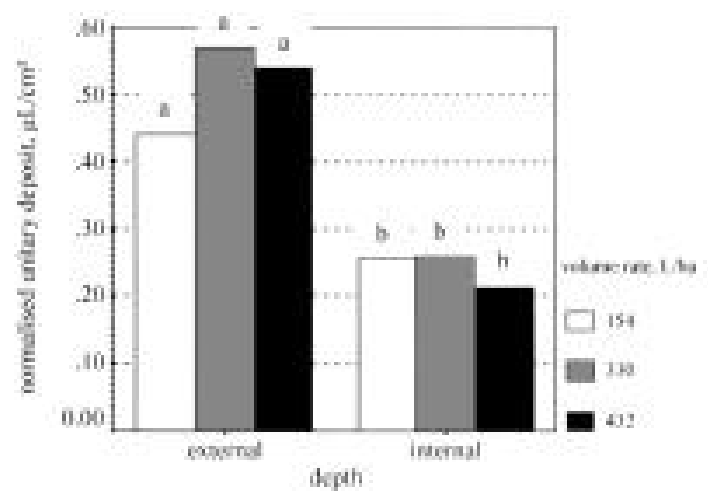

Fig. 15 - Stage 2: Normalised unitary deposit on the two depths. (Mean separation by Tukey's test at 5\% level).

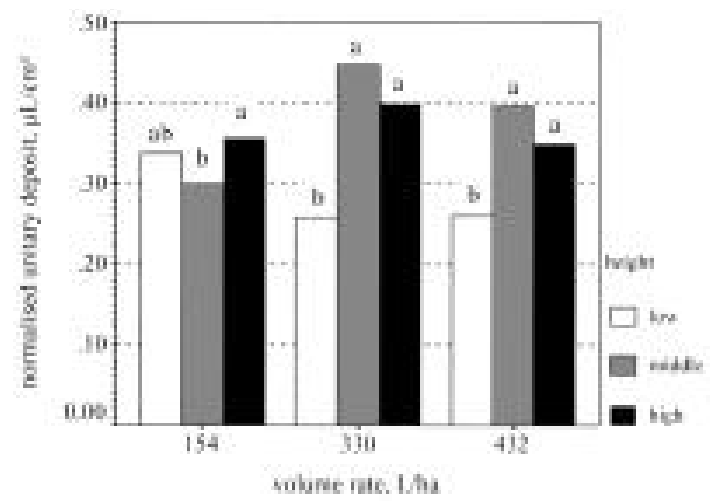

Fig. 16 - Stage 2: Normalised unitary deposit vs volume rate. (Mean separation at each volume rate by Tukey's test at 5\% level). 


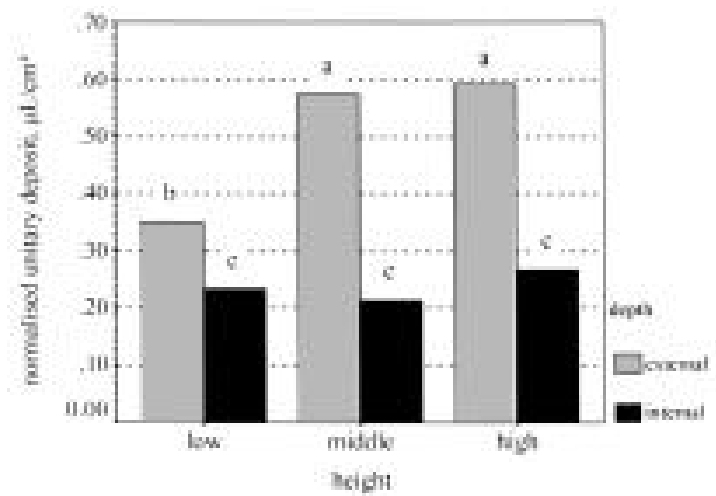

Fig. 17 - Stage 2: Normalised unitary deposit on the three heights (Mean separation by Tukey's test at 5\% level).

\section{Conclusions}

The results, together with those obtained in [2], allow drawing the following conclusions about airflow rate and volume rate:

- reducing airflow rate from 7.5 to $3.9 \mathrm{~m}^{3} / \mathrm{s}$, always results in an increase in the average foliar deposition; the increase is from $+2 \%$ (not significant) to $+52 \%$ (highly significant);

- only in one out of the four experimental trials, increasing the airflow rate led to an improvement of the foliar deposition in the inside part of the canopy at full foliage development;

- volume rates in the range 103-279 L/ha (stage 1) and 154-432 L/ha (stage 2) do not significantly influence the mean foliar deposition in both the two growth stages;

- low volume rate together with high airflow rate, result in a noticeable reduction in foliar deposition ( $29 \%$ with respect the grand mean), due to an increase in the spry drift, especially at the first growth stage;

- the whole results suggest to operate in field at low airflow rates (some $3.9 \mathrm{~m}^{3} / \mathrm{s}$ ) and low volume rates (some 100 or $150 \mathrm{~L} / \mathrm{ha}$, depending on the foliage development, corresponding to $25 \mathrm{~L} /$ ha per active nozzle), so to reduce the power requirements and increase the promptness of intervention.

\section{Acknowledgements}

The Author acknowledges Dr. Giuseppe Emma and Dr. Giuseppe Tornello for their valuable help during the experimental tests.

\section{References}

[1] Cerruto E., Emma G., L'uso dei banchi prova per la regolazione delle irroratrici nei trattamenti in vigneto, Riv. di Ing. Agr., (2005), 3, 45-54.

[2] Cerruto E., Influence of Airflow Rate and Forward Speed on the Spray Deposit in Vineyards, Riv. di Ing. Agr. (2007), 1, 7-14.
[3] Cross J.V., Walklate P.J., Murray R.A., RichardSON G.M., Spray Deposits and Losses in Different Sized Apple Trees from an Axial Fan Orchard Sprayer: 1. Effects of Spray Liquid Flow Rate, Crop Protection, 20 (2001), 13-30.

[4] Cross J.V., Walklate P.J., Murray R.A., RichardSON G.M., Spray Deposits and Losses in Different Sized Apple Trees from an Axial Fan Orchard Sprayer: 3. Effects of Air Volumetric Flow Rate, Crop Protection, 22 (2003), 381-394.

[5] GIL E., Planas S., Preliminary Software to Determine the Optimal Volume Rate for Pesticide Applications in Vineyards, Proceedings of the VII Workshop on Spray Application Techniques in Fruit Growing, 25-27 June 2003, Cuneo, Italy, 121-127.

[6] Pergher G., Gubiani R., The Effect of Spray Application Rate and Airflow Rate on Foliar Deposition in a Hedgerow Vineyard, Journal of Agricultural Engineering Research, (1995) 61, 205-216.

[7] Pezzi F., Rondelli V., The Performance of an Air-assisted Sprayer operating in Vines, J. Agric. Engng. Res. (2000) 76, 331-340.

[8] SAlyani M., FAROOQ M., Effect of Sprayer Airflow on Spray Movement within Tree Canopy, Proceedings of the VII Workshop on Spray Application Techniques in Fruit Growing, 25-27 June 2003, Cuneo, Italy, 227-235.

[9] Walklate P.J., Cross J.V., Richardson G.M., MurRAY R.A., BAKER D.E., Comparison of different Spray Volume Deposition Models using LIDAR Measurements of Apple Orchards, Biosystems Engineering, (2002) 82 (3), 253-267.

\section{SUMMARY}

The present research, continuing that reported in [2], deals with the spray application subject, so to investigate as volume rate and airflow rate, forward speed being equal, affect the foliar deposition in an espalier vineyard. Experimental trials were carried out by means of an air assisted towed sprayer, equipped with "Albuz ATR" nozzles. To take into account the influence of the development of the trees, the field trials were replicated in two phenological stages with an interval of about one month: "Inflorescences fully developed" (stage 1) and "Beginning of berry touch" (stage 2).

A full factorial experiment was carried out for each growth stage, with two airflow rates (3.9 and 7.5 $\left.\mathrm{m}^{3} / \mathrm{s}\right)$, three volume rates $(103,216$, and $276 \mathrm{~L} / \mathrm{ha}$ in the first growth stage and 154, 330 and $432 \mathrm{~L} /$ ha in the second growth stage), and four replicates, arranged according to a randomised complete block design. Working pressure (1.2 $\mathrm{MPa})$ and forward speed $(1.4 \mathrm{~m} / \mathrm{s})$ were kept unchanged for all the trials.

The foliar deposition was measured by means of a spectrophotometric technique. The leaves were sampled on two depth layers and two or three heights, according to the trees' development.

The results showed that volume rate did not significantly influence the mean foliar deposition in both the two growth stages, while the highest deposits were obtained with the lowest airflow rate. 
The airflow rate $\times$ volume rate interaction, though not statistically significant, showed that low volume rates together with high airflow rates, result in a noticeable reduction in foliar deposition $(29 \%$ with respect the grand mean), due to an increase of the spry drift, especially at the first growth stage, when the foliar development is little.

These second tests, unlike those described in [2], did not show any positive influence of the airflow rate on the foliar deposition in the inner part of the canopy, so further investigations could be necessary to better understand the results.

The whole results suggest to operate in field at low airflow rates (some $3.9 \mathrm{~m}^{3} / \mathrm{s}$ ) and low volume rates (some $25 \mathrm{~L} / \mathrm{ha}$ per active nozzle), so to reduce the power requirements and increase the promptness of intervention.

\section{Key words:}

Sprayer, Crop protection, Colorimetric analysis. 